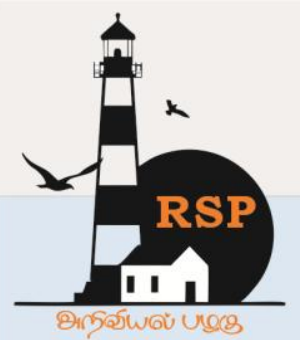

INTERNATIONAL RESEARCH JOURNAL ON ADVANCED SCIENCE HUB

\title{
Design Smart Solar Inverter using e-waste with IOT control
}

Ravindra Parab ${ }^{1}$, Pawan Pandey ${ }^{2}$,

${ }^{1} P G$ Scholar, Dept. of Electrical Engineering, Malwa Institute of Technology, Indore

${ }^{2}$ Assistant Professor, Dept. of Electrical Engineering, Malwa Institute of Technology, Indore ravindra.parab.80@gmail.com ${ }^{1}$

\begin{abstract}
Today is the age of evolution of technology; Innovation will be the key to success in this era of rapid technological advancement and adoption in every area. But matter is that how to make efficient to conventional technology or to make it advance such technology. In present scenario global environmental and energy problems, high expectations exist for solar power generation directly result in to reduce carbon dioxide generation by the primary use of fossil fuels. On the other hand domestic power consumption demand arising day to day. Our aim is to demonstrate solar energy to design smart solar inverter to utilize scrap e-waste. E-waste production is increasing day by day with least solution to reuse it for other purposes. E-waste can be a heavy part of future problems. The inverter is made by the help of most of e-waste material. This 500W solar micro inverter consists of three portion: the MPPT (Maximum Power Point Tracker) the DC-to-AC step-up converter and the AC-DC Inverter sections. In this paper, the attachment of hi-tech application (Data Acquisition System) using ESP8266/32 \& sensor which helps to monitor temperature, battery position \& light position to protect overall system environmental-friendly. Environmental friendly term hype for which the paper and the device totally support it, with equal importance. At the end, the inverter made up of e-waste but also with the application of IOT (Internet of things) can help to control the inverter from anywhere and regulate our safety concerns.
\end{abstract}

Keywords:E-waste, IOT, Inverter, ESP8266/32, LDR, LM35, MPPT

\section{Introduction}

As electronics waste is a concern problem raising rapidly, it now creating heavy adverse effects. Reusing e-waste is not possible for us now completely. From our experiences e-waste require special attention and to prevent e-waste more efforts then normal is required. With efforts investment in the field of recycling and reusing by an industry should be a considerable option. Every component in electric circuit required different process or attention for reusing. In this paper, use of IOT on a e-waste inverter from scrap is used for showing an example and define it can again work with some special treatment. Such inverter requires certain different attention to make a circuit. Circuit completed with different component specified in paper. The inverter work on two different phase of main power supply. First phase is the power from the electric current and second by taking power from solar panel. The clearer the application is that, when due to weather the sunlight is not have a tendency to charge the inverter it directly going to switch itself on the main power supply. From which we can see, energy can be saved in heavy manner by not using main power. The whole inverter is directly connected to an IOT source. The IOT source directly helping us make sure the surveillance of its component and the power output measurement, temperature, humidity, voltage current, power factor which can be used to detect the life of inverter and its tendency to tolerate. LDR sensor mainly used as component for detecting light and give us a detection towards the light intensity which can help solar panel judgment of available of light. Mosfet helping to convert AC to DC conversion in connection with transformer. LM317 as IC helping in voltage regulator. Its 


\section{www.rspsciencehub.com}

function to work on variable value, so that its voltage can be adjusted as per our requirement.[15]

\subsection{E-waste}

Electronic waste (e-Waste) is a common and casual term that openly applies to all white products, consumer and business electronics, and hardware for information technology that is at the end of its useful life. A vast and increasing range of electronic products, from large home appliances such as refrigerators, air conditioners, mobile phones, stereos and consumer electronics to computers. E-Waste also can be defined as any appliance of electrical capacity that has reached its end-of-life.[3-8]

\subsection{IoT Ecosystem}

An IoT ecosystem consists of web-enabled smart devices that use embedded systems, such as processors, sensors and communication hardware, to collect, send and act on data they acquire from their environments. IoT devices share the sensor data they collect by connecting to an IoT gateway or other edge device where data is either sent to the cloud to be analysed or analysed locally. Sometimes, these devices communicate with other related devices and act on the information they get from one another. The devices do most of the work without human intervention, although people can interact with the devices -- for instance, to set them up, give them instructions or access the data.[3034]

\section{Literature Survey}

As per my literature and daily life survey, in this paper we are presenting those which are not that much familiar or not easily can be seen as a consideration of electronics waste: -

1. Students during practice at electronic laboratories use different IC's and due to lack of knowledge and skills, they damage different component. Shortage of IC's is not only present in educational field. As a student and professional, I acknowledged this reason from very long time. Seen bulk of electronics components in waste gave out from the industries. From small components to bulky components, every electronics waste have a level from where it can't be repairable due to age limit of its tendency to bear electric current and voltage.
Volume 03 Issue 01 January 2021

2. When satellite released from earth, it is not a big problem that batteries and IC have life span. Because, countries want to be best and be on top in every race they are not worry about the electronic waste in space. Battery, IC's, Semiconductors and so many various components have certain life span to give feedback and work with highly recommendable condition. When the life span completed by them, then there is no one who's replacing them or taking back on earth to reuse somehow.

3. Every home these days have toys for their children or gadgets with chip, when it goes out of working condition then we don't put our efforts to repair the same.

In given literature review, each review is from different region and different perspective. The reviews are as follows: -

1. Emon, Imran, and AfsanaMonmila. "Electronic Waste Management Can Be the Biggest Challenge in Bangladesh." ICBM (2019).

ESDO conducted a research survey on the topic of e-waste and the development of a mass awareness and learning program on e-waste through a project based on Dhaka and Chittagong City. According to a recent report by the University of Engineering and Technology of Bangladesh, Bangladesh generates around 400,000 metric tons of this ewaste annually (BUET).[9-15]

2. "Recycling of e-waste in China may expose mothers, infants to high dioxin levels, science news," 2007.

Alarming amounts of dioxin compounds associated with cancer, developmental disorders and other health issues have been detected. These compounds are associated with excessive disposal of electrical goods in breast milk, placenta and hair samples.

\section{E-waste components in circuit}

In circuit, majority of component are taken from scrap. Some components from different not working product, which are used in a way to consume them in great way. The components are as follows: -
a. Solar Panel
b. Transistor
c. Mosfet
d. Regulated IC
e. Relay
f. PCB 


\subsection{Component Description}

A solar cell is a solid state electrical device which, through the photovoltaic effect, converts the energy of light directly into electricity. Solar panels are classified as assemblies of cells used for producing solar modules that are used to collect energy from sunlight. Solar panels do not burn fuel and have no moving components, meaning they are safe and quiet and do not produce greenhouse gases emissions from the atmosphere.[16-24]

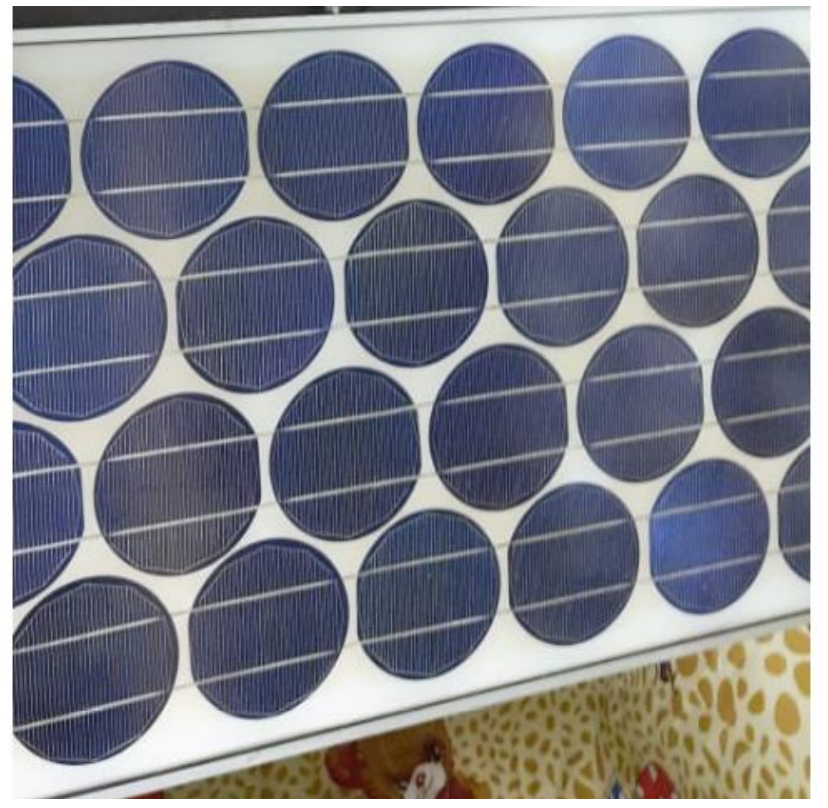

Fig.1. Solar Panel

A field-effect transistor metal-oxide semiconductor is a special type of field-effect transistor that operates by electronically changing the width of a channel along which the movement of charge carriers (electron or hole) flows. The larger the channel, the best the unit works. At the source, the charge carriers enter the channel and exit through the drain. The channel diameter is regulated by the voltage on an electrode called the tube, which is physically located between the source and the drain and is shielded by an extremely thin layer of metal oxide from the pipe.[25-30]

A transistor is a semiconductor component used for electronic signals and electrical power amplification or switching with at least three external circuit communication terminals. A voltage-current applied to one pair of terminals of the transistor affects the current through another pair of terminals. A transistor can amplify a signal since the controlled power can be greater than the controlling power.

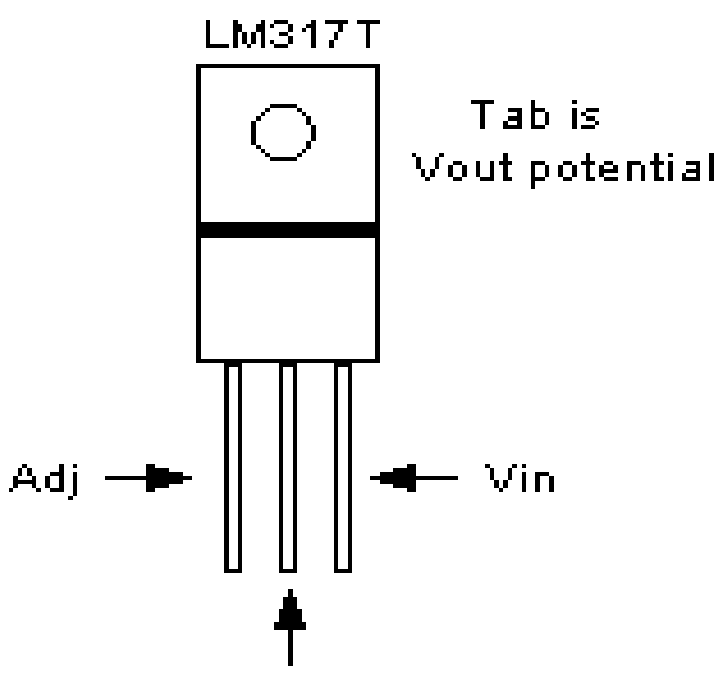

Fig.2. LM317 pin diagram

Signetic Corporation launched the 555 timer IC in the year 1970. Basically, it is a monolithic timing circuit that generates time delays or oscillations that are reliable and extremely stable. The 555IC is also similarly effective and is inexpensive in price. It can also be used in dc-dc converters, optical logic probes, waveform generators, analog frequency meters and tachometers, temperature measurement and control systems, voltage regulators, etc, in addition to its uses as a monostable multivibrator and astable multivibrator.

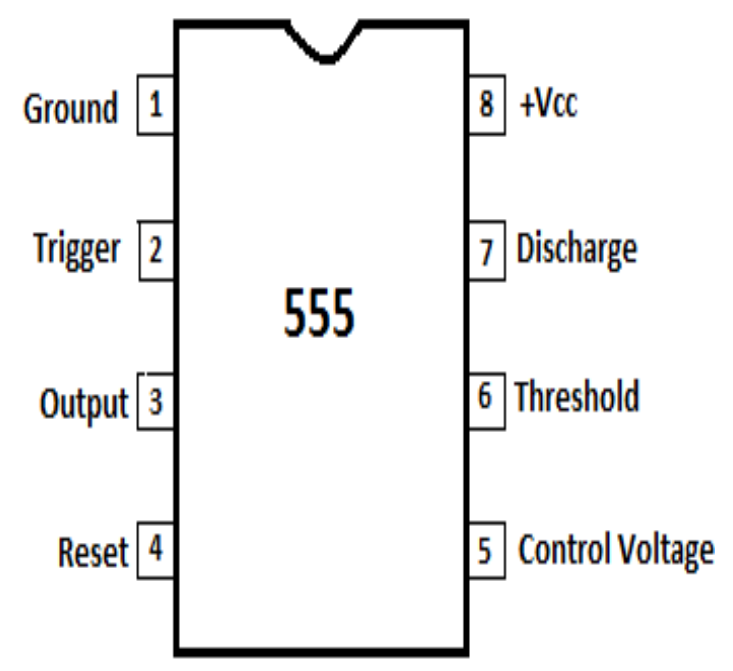

Fig.3. IC555 pin diagram

A Relay is an electromechanical mechanism which can be used to establish an electrical link or to 
sever it. It consists of a versatile moving mechanical component that can be operated electronically by an electromagnet. Essentially, a relay is like a mechanical switch, except instead of turning it on or off manually, you can trigger it with an electronic signal. Again this working principle of relayfits only for the electromechanical relay.

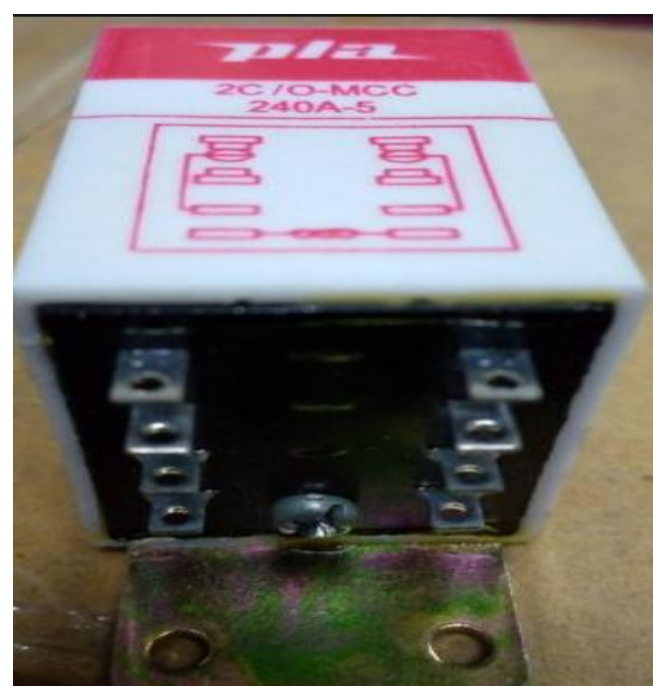

Fig.4. PLA RELAY

A printed circuit board (PCB) uses conductive tracks, pads and other features to mechanically sustain and electrically link electrical or electronic parts, etched from one or more sheet layers of copper laminated to and/or between sheet layers of a non-conductive substrate.

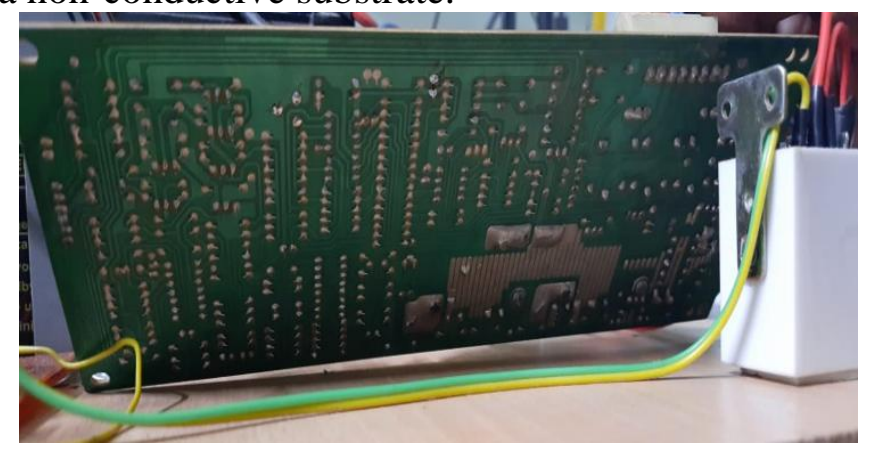

Fig.5. PCB

\section{Hardware Requirements}

Components used for working inverter: -

1.ESP8266/32

2.SG3524

3.LM339

4.IC555

5.LM35
6.LDR

7.LM317

8.LM7805

9.ICLM358

10.IC741

Description of some components are as follows:-

\section{1.SG3524}

The SG3524 IC integrates all the functions necessary for the single chip construction of a controlling power supply, inverter or switching controller. For high-power-output applications, SG3524 can also be used as the control feature.

Applications of SG3524:-

1. Desktop PCs

2. Microwave Ovens

3. Server PSUs

4. Solar Micro-Inverters

5. Washing Machines: Low-End and HighEnd

6. E-Bikes

7. Power: Telecom/Server AC/DC Supplies:

8. Smoke Detectors

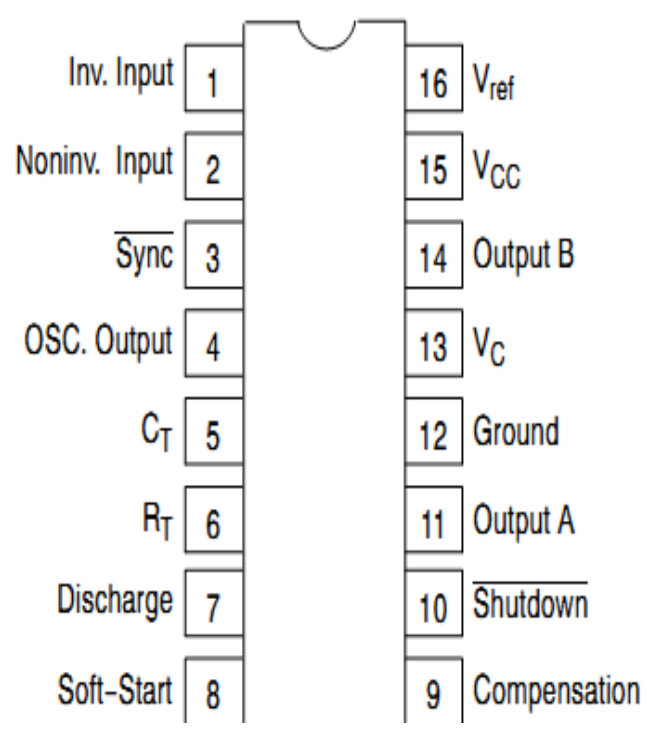

Fig.6. SG3524 pin diagram

\section{2.LDR}

In general, the monitoring of lighting and home appliances is manually operated and controlled on a variety of occasions. However, due to the carelessness of human beings or uncommon conditions, the method of regulating appliances can cause power wastage. We may use the lightdependent resistor circuit to monitor loads based on 
the strength of light to solve this problem. It is made up of high resistance semiconductor material.

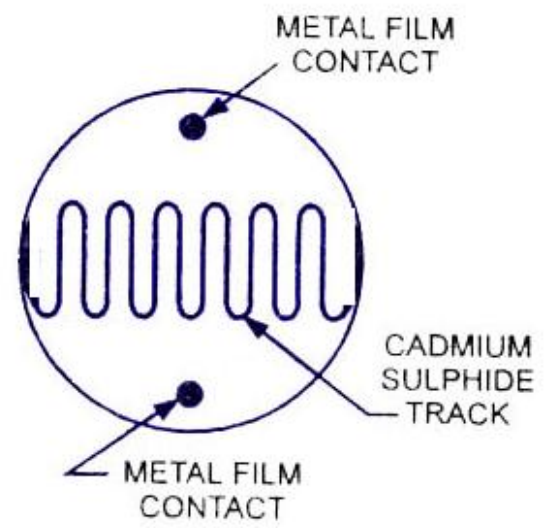

Fig.7. LDR pin diagram

\section{3.LM7805}

7805 is a $5 \mathrm{~V}$ fixed output voltage three-terminal linear voltage regulator IC that is useful in a wide variety of applications. The 7805 Voltage Regulator IC is currently manufactured by Texas Instruments, ON Semiconductor, STMicroelectronics, Infineon Technologies, Diodes Inc., etc.

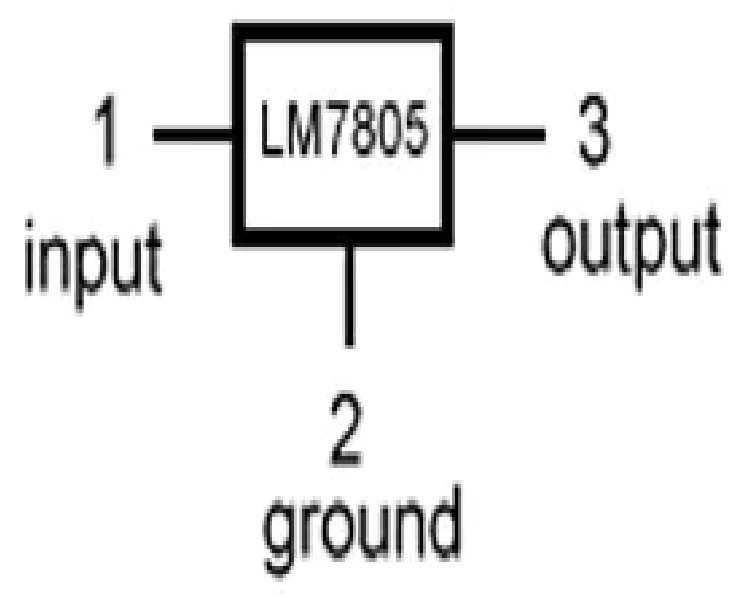

Fig.8. LM7805 pin diagram

\section{4. Node MCU (ESP8266)}

The ESP8266 features an 802.11b/g/n HT40 Wi-Fi transceiver, allowing it not only to connect to and communicate with the Wi-Fi network, but also to set up its own network, allowing other users to connect directly to it. This makes the Node MCU ESP8266 much more versatile.

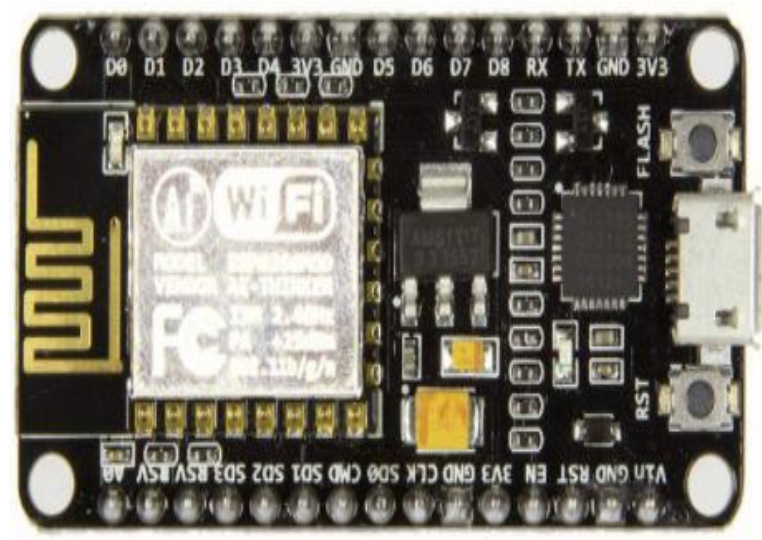

Fig.9. Node MCU (ESP8266)

\section{Methodology}

The methodology contains different parts description and feature use and its requirement in the circuit. It is as follows: -

1.The inverter is taken from scrap, to justify the e-waste. The inverter precondition is without battery, but the circuit is well up to the mark. The inverter was in waste because of the no knowledge of the field. The electronic component complexity is cannot be recognized by any one on simpler manner.

2.Other components used in the complete package helping here to use our inverter up to full length. The lack of battery in inverter in scrap, is task to find same capacity due to parts specification.

3.LDR justify its feature to detect the humidity and temperature, to know the solar panel working is proper or not.

4.Solar panel is directly charging our inverter through sun light. At the time the weather is bad, the inverter main power supply switch by relay. Function of Relay directly helping whole package to work on continuous non stoppable function.

5.Capacitor is added with battery of inverter so that the efficiency of components as well as battery during weaken or not regulate current and voltage, which may can damage PCB.

6. MPPT (maximum power point tracker) use for regulate the voltage and current during attenuation. The reason of using it to optimize the supply in 
proper manner, so that the efficiency of panel and other component will not get affected.

7.IOT (internet of things) use is to manage or control the unit from anywhere. As the pandemic taught us to move more towards the IOT, by using this control feature we can manage the safety of our home, factory or any other place where, such system is installed.

\section{Working of Inverter with IOT}

The working of inverter is not affected by the main idea of this paper to combine effort of e-waste with IOT. Inverter work in same as the conventional one. But, the charging of battery have different type of input. The input have featuring from sunlight through solar panel. Solar panel can charge the battery with its full capacity. MPPT as component helping to maintain the current and voltage. The other source going to be active when there is no reach of sunlight or due to bad weather. LDR sensor is the one which help to shift the battery power source from sunlight to home power supply. The inverter connected to the IOT circuit for controlling from different places. The main reason to add IOT in this idea is safety. We can operate the inverter as per our need from anywhere around the world and control it at the time of malfunctioning to prevent disaster. IOT system sensing temperature, humidity, power and current difference to understand the state of inverter. Inverter circuit is gained from scrap, which was not in condition to work with malfunctioned battery only. By using an old battery, we reused many components. Reusing give more to use such circuit for longer then we think.[30-36]

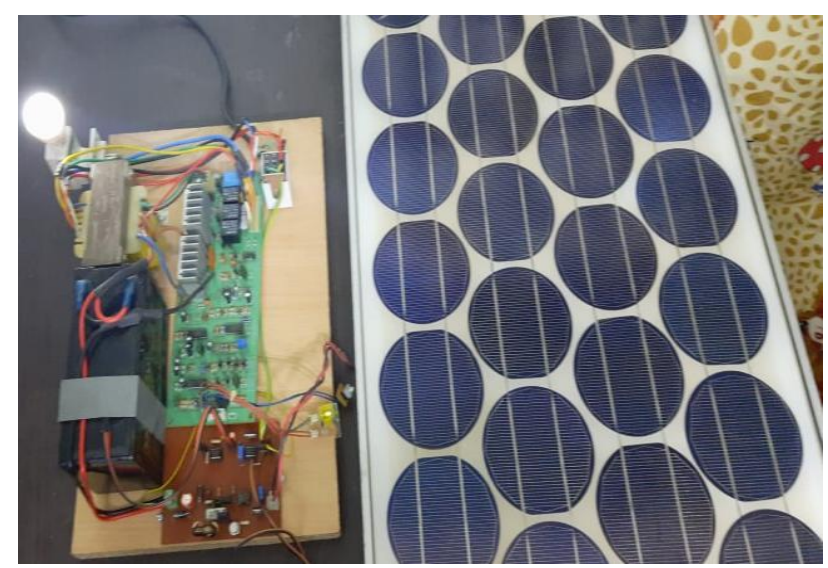

Fig.10. Inverter Circuit
Inverter Specification:-

Power Output - 500 watt

Output Voltage - 240volts $/ 50 \mathrm{~Hz}$

DC Battery input voltage -12 volt 7Ah

Solar Panel output - 18volt DC/75watt

Solar Panel output during load - 13 volt

Low battery cut off -10.5 volts

Output waveform type - Quasi Square wave Input Voltage - 240volts/50Hz

\section{Conclusions}

In this paper, we tried to use electronic waste as an application. E-waste is a concern for industries these days. The concern which can become a nightmare for us in future. From bulky requirement of computers by IT company and its component malfunctioning creating load on company storage units. If electronic waste used in such manner that it can be a reusable or long use, so that the manufacturing or new component can be slow down and the extraction and so many other process in industries can reduce heavily to pollution and unnecessary production services. The combination of E-waste, Solar energy and electronic circuit with IOT show us how we can reduce, reuse and surveillance which can break many conventional thinking in terms of production. This can be method to cooperate between renewable resource and non-renewable resource can challenge previous terminology to use newer component and old power supplies.

\section{References}

[1].Admin, W. (Ed.). (2017, May 25). Impacts of E-Waste on the environment - E-Terra Technologies Limited. Retrieved from http://www.eterra.com.ng/articles/impacts-ewaste-environment.

[2].Amin, M. A. (2019, April 10). E-waste management: No progress in 7 years since regulations drafted. Retrieved fromhttps://www.dhakatribune.com/banglades h/environment/2018/10/19/e-wastemanagement-no-progress-in-7-years-sinceregulations-drafted.

[3]. Aowsaf, S. A. (2018, February 15). Treasure from trash: E-waste recycling in Bangladesh. Retrievedfromhttps://www.dhakatribune.com/o pinion/special/2018/02/15/treasure-trash-ewaste-recycling-bangladesh. 


\section{www.rspsciencehub.com}

[4].Parvez, S. (2019, January 24). Electronic waste disposal rules on the cards. Retrieved from Electronic waste disposal rules on the cards.

[5].Lubell, I. (2018, April 27). 5 Shocking Environmental Effects of E-Waste [Web log post].

Retrieved fromhttps://info.mayermetals.com/blog/5shocking-environmental-effects-of-e-waste.

[6].Eye on e-waste. (2019, February 03).

[7].Florin-Constatin Mihai and Maria-Grazia Gnoni (June 29th 2016). E-waste Management as a GlobalChallenge (Introductory Chapter), E-Waste in Transition - From Pollution to Resource, Florin-Constantin Mihai, IntechOpen, DOI: 10.5772/64596.

[8].DanielMmereki, Baizhan Li, Andrew Baldwin and Liu Hong (June 29th 2016). The Generation, Composition, Collection, Treatment and Disposal System, and Impact of E-Waste, E-Waste in Transition -From Pollution to Resource, Florin-Constantin Mihai, IntechOpen, DOI: 10.5772/61332.

[9].Emon, Imran, and AfsanaMonmila. "Electronic Waste Management Can Be the Biggest Challenge in Bangladesh." ICBM (2019).

[10]."Recycling of e-waste in China may expose mothers, infants to high dioxin levels, science news," 2007 , http://www.sciencedaily.com/releases/2007/10/ 071022094520.htm.

[11].L. M. Hilty, "Electronic waste - an emerging risk?" Environmental Impact Assessment Review, vol. 25, no. 5, pp. 431-435, 2005.

[12].UNEP, Recycling-From e-Waste to Resources: Sustainable Innovation and Technology Transfer Industrial Sector Studies, United Nations Environment Programme, 2009.

[13].Consumer Electronics Association, "US consumer electronics sales and forecast, 20032008," 2008.

[14]. Euromonitor from Trade Sources/national statistics, Euromonitor International, 2010.

[15]. J. Watts, "China orders PC makers to install blocking software," 2009

[16]. W. He, G. Li, X. Ma et al., "WEEE recovery strategies and the WEEE treatment status in China," Journal of Hazardous Materials, vol. 136, no. 3, pp. 502-512, 2006.
Volume 03 Issue 01 January 2021

[17].UNEP, E-waste: The Hidden Side of IT Equipment's Manufacturing and Use: Early Warnings on Emerging Environmental Threats no. 5, United Nations Environment Programme, 2005.

[18]. D. Woodell, “GeoPedia: e-waste," National Geographic, 2008

[19]. D. Woodell, "High-tech trash," National Geographic, pp. 72-73, 2008.

[20]. CBC News, "How much e-waste do you dump? Cheryne's Diary," 2007, http://cheryne.blog.ca/2008/05/21/e-waste4200920/.

[21]. D.S. Chauhan, S.K Srivastava, NonConventional Energy Sources, New Age International, 2010, 2nd edition

[22]. Solar Energy: Fundamentals, Design, Modelling and Application (Revised Edition) by Tiwari G N, Narosa Publishing House Pvt. Ltd. - New Delhi (2012)

[23]. Solar Photovoltaic Technology and Systems: A Manual for Technicians, Trainers and Engineers by Solanki C.S, Prentice Hall India Learning Private Limited (2013)

[24]. Physics of Solar Cells - A Text for Undergraduates, by J Nelson, Imperial College Press, 2003

[25]. Power Electronics: Circuits, Devices and Applications (English) 3rd Edition by Muhammad H. Rashid, Pearson 2003

[26]."Analysis and Modeling of Transformer less Photovoltaic Inverter Systems," by Tamas Kerekes, Aalborg University Institute of Energy Technology Denmark, August 2009

[27]. A. Megha Joshi, S. Kavyashree, "IoT Based Smart Inverter Using Raspberry PI',International Journal of Latest Technology in Engineering, Management \& Applied Science, 2017

[28].AchimWoyte, MauricioRichter, David Moser,StefanMau, NilsReich, UlrikeJahn “ Monitoring Of Photovoltaic Systems, Good Practices And Systematic Analysis", 28th European PV Solar, 2016

[29]. Aoi Hashizume, Tandanori Mizuno and Hiroshi Mineo, "Energy Monitoring System using Sensor Networks in Residential Houses," in proc. of 26th IEEE International Conference on Advance Information 
Networking and Application Workshop, June 2012.

[30].Byeongkwan Kang, Sunghoi Park,T acklim Lee, and SehyunParkChung, "IoT-based Monitoring System using Tri-level Context Making Model for Smart Home Services", in proc. ofIEEE International Conference on Consumer Electronics, 2015

[31].Chen Peijiang, Jiang Xuehua, "Design and Implementation of Remote Monitoring System Based on GSM", in proc.of IEEE Pacific-Asia Workshop on Computational Intelligence and Industrial Application, 2008

[32].G.A. Rathy, and P.Sivasankar, "IoT based Classroom Automation using Zigbee", International Journal of Innovative Science, Engineering \& Technology, Vol. 6 Issue 3, March 2019, pp.98-102

[33].[33]H.Divya. "Solar smart inverter: A novel design using multi-level topology and pulse width modulation with load detection.'International Journal of Engineering Research \& Technology, 2015.

[34].N. Santhoshkumar, B.Sasikumar, "IoT BASED SMART INVERTER", International Journal of Advanced Science and Engineering Research, 2017.

[35].O.I. Adekola, A. K. Raji, "Functionalities of smart inverter system for grid-connected applications". In proc. OfInternational Conference Industrial and Commercial Use of Energy, 2015

[36].Oussama BEN BELGITH, Lasaad SBITA, "Remote GSM module monitoring and Photovoltaic System control", in proc. of First International Conference on Green Energy, 2014 